\title{
Perancangan Aplikasi Mobile Learning Untuk Membantu Proses Pembelajaran Di SDN Lemahireng 03
}

\author{
Arfa Yustian $^{1}$, Sri Yulianto ${ }^{2}$ \\ ${ }^{1,2}$ Universitas Kristen Satya Wacana; Jl. Diponegoro 52-60, Salatiga 50711, Indonesia, Fax. 321433 \\ ${ }^{3}$ Jurusan Teknik Informatika, FTI UKSW, Salatiga \\ e-mail: ${ }^{1}$ 672016214@ student.uksw.edu, ${ }^{2}$ sri.yulianto@uksw.edu
}

\begin{abstract}
Abstrak
Pendidikan merupakan tonggak bagi peradaban suatu bangsa. Terlepas dari itu perkembangan teknologi informasi yang semakin pesat di era globalisasi saat ini tidak bisa dihindari lagi pengaruhnya terhadap dunia pendidikan. Seiring dengan perkembangan teknologi informasi khususnya internet dalam sistem informasi, proses belajar mengajar telah memanfaatkan teknologi informasi tersebut baik dari jenjang pendidikan dasar. Inovasi-inovasi baru mucul untuk menunjang kegiatan pembelajaran sebagai dampak dari perkembangan teknologi. Salah satu dari inovasi tersebut penggunaan smartphone menjadi sebuah media pembelajaran yang menarik dan menyenangkan apabila diisi sebuah aplikasi dan kontenkonten edukasi. Penggunan smartphone telah meluas hingga ke berbagai macam kalangan, hingga ke peserta didik yang kini telah menggunakannya. Dengan ini diharapkan penelitain dengan pembuatan aplikasi mobile e-learning sistem informasi sehingga membantu memaksimalkan proses belajar siswa secara mudah.
\end{abstract}

Kata kunci: E-learning, mobile application, smartphone.

Abstract
Education is a milestone for a nation's civilization. Apart from that, the development of information technology is increasingly rapid in the current era of globalization and its impact on the world of education is inevitable. Along with the development of information technology, especially the internet in information systems, the teaching and learning process has made use of this information technology up to the basic education level. New innovations appear to support learning activities as a result of technological developments. One of these innovations is the use of a smartphone to become an interesting and fun learning medium when it is filled with an application and educational content. The use of smartphones has expanded to various groups, to students who have now used them. With this, it is hoped that research with the creation of an information system e-learning mobile application will help maximize the student learning process easily.

Keywords: E-learning, mobile application, smartphone.

\section{PENDAHULUAN}

Pendidikan merupakan tonggak bagi peradaban suatu bangsa. Maka maju atau mundurnya peradaban suatu bangsa sangat ditentukan oleh kualitas pendidikannya. Kualitas pendidikan yang baik akan melahirkan sumber daya manusia yang baik begitupun sebaliknya[1]. 
Perkembangan teknologi informasi yang semakin pesat di era globalisasi saat ini tidak bisa dihindari lagi pengaruhnya terhadap dunia pendidikan. Tuntutan global menuntut dunia pendidikan untuk selalu dan senantiasa menyesuaikan perkembangan teknologi terhadap usaha dalam peningkatan mutu pendidikan, terutama penyesuaian penggunaannya bagi dunia pendidikan khususnya dalam proses pembelajaran[2]. Proses belajar mengajar merupakan proses yang melibatkan peserta dan pendidik. Proses belajar mengajar akan berhasil apabila adanya interaksi antara kedua pihak. Seiring dengan perkembangan teknologi informasi khususnya internet dalam sistem informasi, proses belajar mengajar telah memanfaatkan teknologi informasi tersebut baik dari jenjang pendidikan dasar, menengah maupun pendidikan tinggi[3].

Perkembangan teknologi yang merata dan semakin marak disetiap bidang kehidupan termasuk dalam bidang Pendidikan memaksa umat manusia untuk mengikuti laju perkembangan teknologi. Dalam pendidikan abad 21 teknologi sudah menjadi pelengkap utama dalam setiap kegiatan pembelajaran. Inovasi-inovasi baru mucul untuk menunjang kegiatan pembelajaran sebagai dampak dari perkembangan teknologi[4]. Melalui berbagai keunggulan yang dimiliki, teknologi komputer telah menginspirasi banyak ahli di bidang Pendidikan untuk memberdayakannya dalam skala yang lebih luas, sehingga tidak terbatas dalam pembelajaran semata, tapi menjadi piranti utama dalam penyelengaraan pendidikan[5].

Sehingga perlu adanya peningkatan bersama dalam metode pembelajaran, komunikasi dan interaksi antara siswa dan guru yang memudahkan aktifitas berbagi (sharing) sumber pembelajaran dan aktifitas diskusi tanpa terhalang oleh waktu dan ruang[6]. Penggunaan media dalam proses belajar mengajar dapat membantu kelancaran, efektivitas, dan pencapaian tujuan efisien pembelajaran. Media salah satu komponen yang tidak bisa diabaikan dalam mengembangkan sistem pembelajaran yang sukses[7]. Penggunan smartphone telah meluas hingga ke berbagai macam kalangan, tidak hanya digunakan oleh orang dewasa ataupun orang tua. Akan tetapi, sudah meluas hingga ke peserta didik yang kini telah menggunakannya[8].

Smartphone bisa dimanfaatkan menjadi sebuah media pembelajaran yang menarik dan menyenangkan apabila diisi sebuah aplikasi dan konten-konten edukasi. Penggunaan perangkat mobile berupa smartphone dalam media pembelajaran ini dinamakan mobile learning. Mobile learning merupakan salah satu alternatif pengembangan media pembelajaran[9]. Salah satu prinsip psikologi pendidikan menyebutkan bahwa guru tidak bisa begitu saja memberikan pengetahuan kepada siswa, tetapi siswalah yang harus aktif membangun pengetahuan dalam pikiran mereka sendiri[10].

Berdasarkan latar belakang diatas, penelitian ini dilakukan untuk membantu proses pembelajaran sekolah agar dapat meingkatkan kemampuan siswa dengan bantuan teknologi informasi yaitu e-learning sistem informasi kepada siswa sebagai media informasi sehingga membantu memaksimalkan proses belajar siswa secara mudah.

\section{METODE PENELITIAN}

\subsection{Kajian Pustaka}

2.1.1 Penelitian Terdahulu

Sharippudin dkk (2019). Perancangan Aplikasi E-Learning Pada MTS Negeri 1 Merangin. Hasil dari penelitian ini adalah sebuah aplikasi e-learning yang dapat memberikan kemudahan pada siswa untuk mengakses materi pelajaran meski tidak ada pertemuan di kelas dan sebagai solusi alternatif bagi guru untuk tetap dapat memberikan materi meski tidak bisa hadir saat jam pelajaran [11].

Wahyu dkk (2017). Perancangan E-Learning Berbasis Web Pada SMP Negeri 3 Patuk Gunungkidul Yogyakarta. Dalam penelitian ini, akan dirancang E-Learning berbasis web 
sebagai sarana pendukung proses belajar mengajar antara guru dan siswa yang dapat diakses dimana saja dan kapan saja. Metode penelitian untuk mengumpulkan data yang dilakukan antara lain wawancara, observasi, dan studi Pustaka [12].

Teuku dkk (2017). Pengembangan Aplikasi Sistem E-Learning Pada Seluruh Mata Kuliah Dengan Menggunakan Program Hypertext Prepocessor (PHP) Dalam Rangka Peningkatan Mutu Proses Dan Hasil Pembelajaran [13].

\subsubsection{Aplikasi Mobile}

Aplikasi mobile berasal dari dua kata, yaitu aplikasi dan mobile. Secara istilah, aplikasi adalah program siap pakai yang dibuat untuk melaksanakan suatu fungsi untuk pengguna atau aplikasi yang lain sedangkan mobile adalah perpindahan dari suatu tempat ke tempat yang lain. Secara lebih lengkap, aplikasi mobile adalah program siap pakai yang melaksanakan fungsi tertentu yang dipasang pada perangkat mobile [14].

\subsubsection{Android}

Android adalah sebuah software open-source untuk berbagai perangkat mobile. Android adalah sistem operasi untuk perangkat mobile yang berbasis Linux dan dikembangkan oleh Google. Aplikasi - aplikasi android dapat di - download dari Google Play, baik secara berbayar maupun gratis [15].

\subsubsection{Fluter}

Flutter adalah SDK untuk pengembangan aplikasi mobile yang dikembangkan oleh Google. Sama seperti react native, framework ini dapat digunakan untuk membuat atau mengembangkan aplikasi mobile yang dapat berjalan pada device iOS dan Android. Dibuat dengan menggunakan $C, C++$, Dart, dan Skia membuat flutter ini menjadi salah satu framework yang sangat menarik dan worth [16].

\subsubsection{Firbase}

Firebase adalah penyedia layanan cloud dengan back-end sebagai servis yang berbasis di San Fransisco, California. Firebase membuat sejumlah produk untuk pengembangan aplikasi mobile ataupun web. Firebase didirikan oleh Andrew Lee dan James Tamplin pada tahun 2011, dan. diluncurkan dengan cloud database secara realtime di tahun 2012 [17]

\subsection{Metode Penelitian}

Penelitian ini menggunakan metode Extreme Programming (XP). Model ini melakukan pendekatan secara Object - Oriented. Tahapan-tahapan yang harus dilalui antara lain: Planning, Design, Coding, dan Testing. 


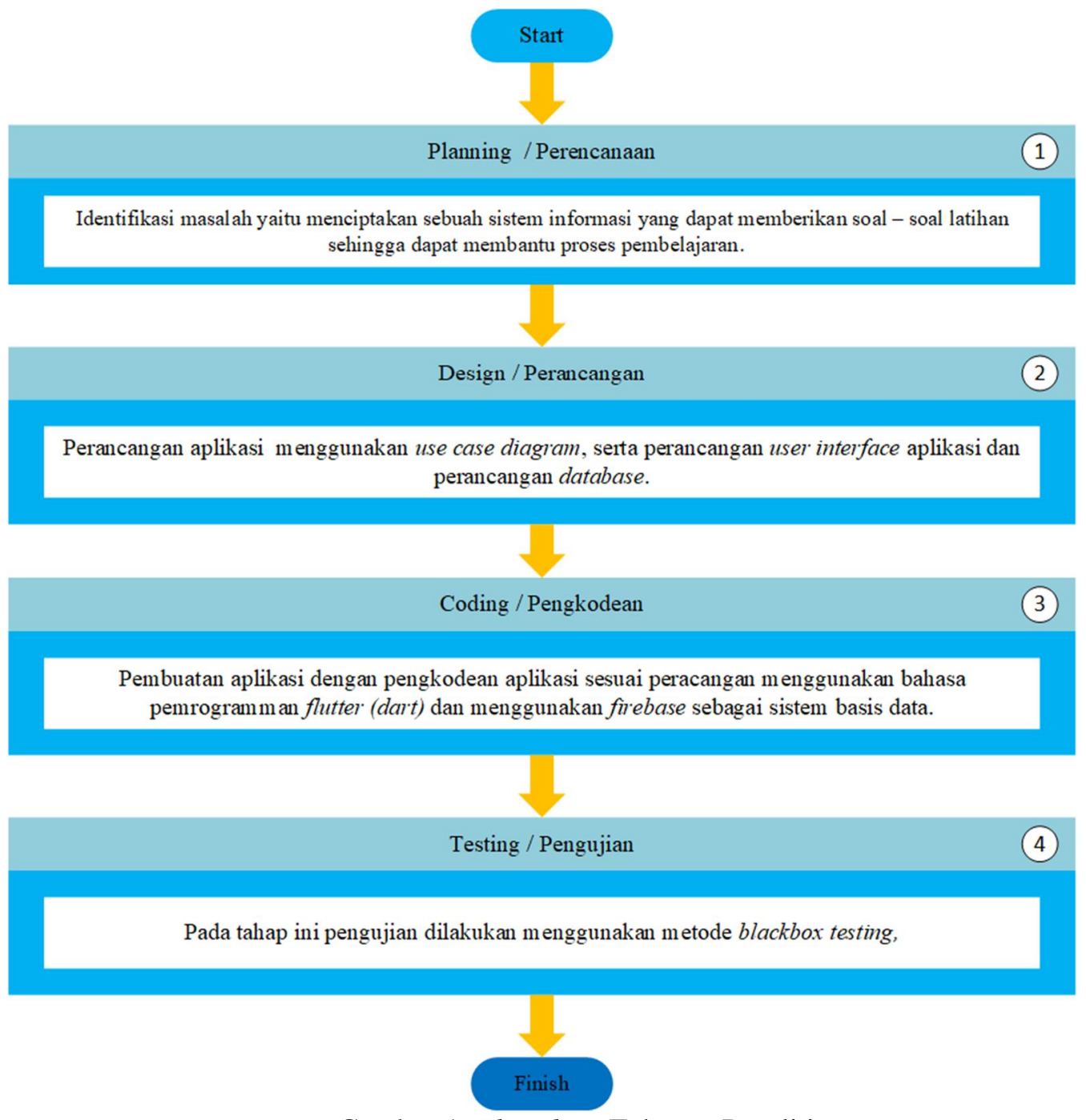

Gambar 1. Flowchart Tahapan Penelitian

Tahap - tahap penelitian pada gambar 1 dapat dijelaskan sebagai berikut:

1. Tahap Perencanaan.

Pada tahapan ini merupakan tahapan awal dalam perancangan sistem dalam penelitian ini, dimulai dengan identifikasi permasalahan, permasalahan pada penelitan ini adalah kurangnya sarana untuk membagikan informasi dalam kegiatan proses pembelajaran antara pengajar dan peserta didik, maka penelitian ini dilakukan untuk menciptakan sebuah sistem informasi yang dapat menyampaikan informasi dalam proses pembelajaran secara cepat, sehingga dapat membantu proses pembelajaran. Kemudian study literatur dari jurnal peneliti - peneliti sebelumnya sesuai dengan topik permasalahan untuk mendapatkan pustaka pustaka yang dapat membantu penelitian, serta analisis sistem yang akan dibangun dalam penelitian ini.

2. Tahap Perancangan.

Pada tahap ini merupakan penekanan pada pada perancangan aplikasi seperti arsitektur sistem, use case diagram, serta activity diagram aplikasi tersebut. 
3. Tahap Pengkodean.

Tahapan ini merupakan kegiatan pembuatan aplikasi dengan melakukan pengkodean sesuai pererancangan aplikasi yang sudah dibuat dengan menggunakan bahasa pemrogramman flutter (dart) dan menggunakan firebase sebagai sistem basis data.

4. Tahap Pengujian

Tahapan pengujian, tahap ini merupakan tahapan terakhir pada penelitian ini, tahap ini dilakukan untuk mengetahui apakah ada kesalahan saat aplikasi dijalankan dan untuk mengetahui apakah aplikasi sudah sesuai dengan kebutuhan dalam kasus penelitian ini. Pada tahap ini pengujian dilakukan menggunakan metode blackbox testing, dimana dilakukan pengecekan ditempat sekolah sebagai tempat pembelajan dan bersama 11 pengajar sebagai pengguna aplikasi ini dengan melakukan simulasi penggunaan aplikasi sesuai kebutuhan dalam kasus penelitian ini, serta pengecekan terhadap fungsi fungsi yang tersedia dalam aplikasi tersebut, selain itu pengajar diberikan kuisioner untuk mengetahui apakah aplikasi ini berhasil memenuhi tujuan dan bermanfaat seperti harapan penelitian ini.

\subsubsection{Arsitektur Sistem}

Arsistektur sistem adalah sebuah model yang menggambarkan struktur suatu sistem. Dengan tujuan agar struktur yang dirancang dapat menjawab kebutuhan pengguna.

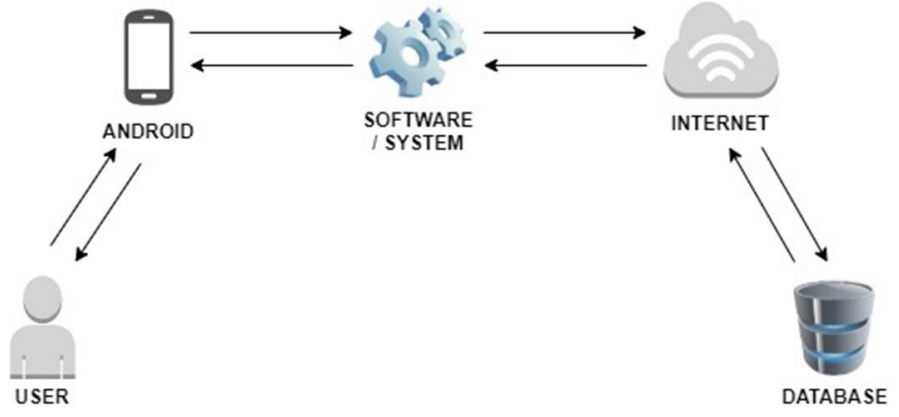

Gambar 2. Arsitektur Sistem

Pada gambar 2 Merupakan perancangan arsitektur dari sistem aplikasi pembelajaran online. Data akan dikirim melalui internet setelah data dikirim nantinya akan ditampilkan sebuah informasi.

\subsubsection{Use Case Diagram}

Use Case Diagram merupakan diagram yang mendeskripsikan sebuah interaksi antara aktor dengan sistem yang dibuat. Use Case juga digunakan untuk mengetahui fungsi apa saja yang ada.

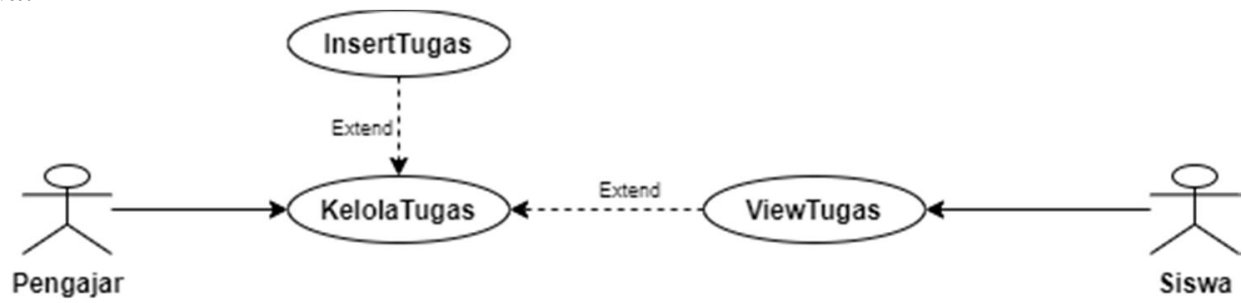

\section{Gambar 3. Use Case Diagram}

Pada gambar 3 dapat dijelaskan User pengajar berperan sebagai pengelola aplikasi seperti memberikan tugas ataupun pengumuman dalam pembelajaran kepada siswa, sehingga siswa dapat melihat tugas ataupun pengumuman dalam pembelajaran yang telah ditambahkan oleh pengajar.

Yustian, et., al [Perancangan Aplikasi Mobile Learning Untuk Membantu Proses Pembelajaran Di SDN Lemahireng 03] 


\subsubsection{Class Diagram}

Class Diagram adalah jenis diagram yang paling berguna di $U M L$, hal ini karena dapat dengan jelas memetakan struktur sistem tertentu dengan memodelkan kelas, atribut, operasi serta hubungan antar objek.

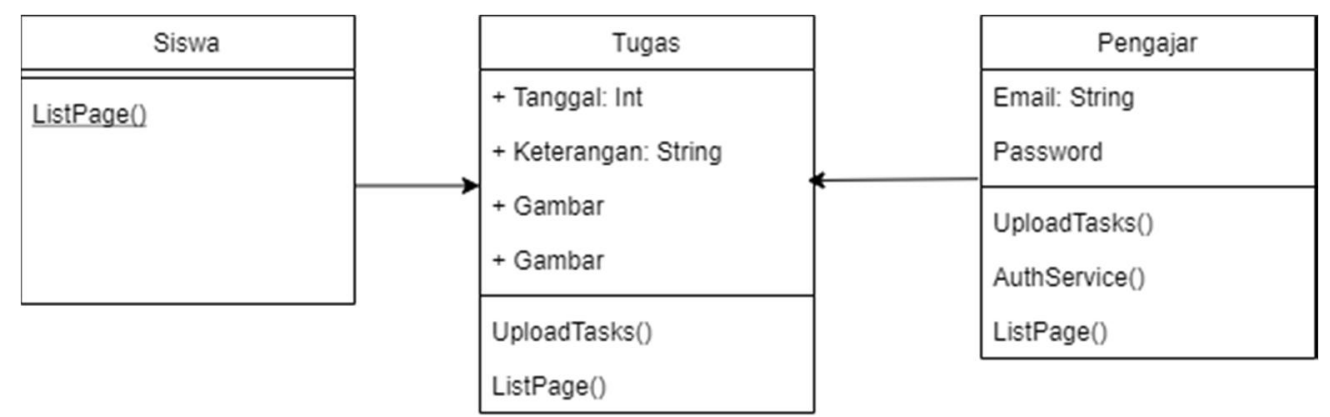

Gambar 4. Class Diagram

Pada gambar 4 dapat dijelaskan hubungan objek yang terdapat pada penelitian ini, dimana tugas menjadi objek pentingnya.

\subsubsection{Activity Diagram}

Activity Diagram adalah diagram yang menggambarkan langkah - langkah pada proses sistem yang dibuat dari awal sampai akhir. Activity Diagram juga menggambarkan alur tampilan sistem.

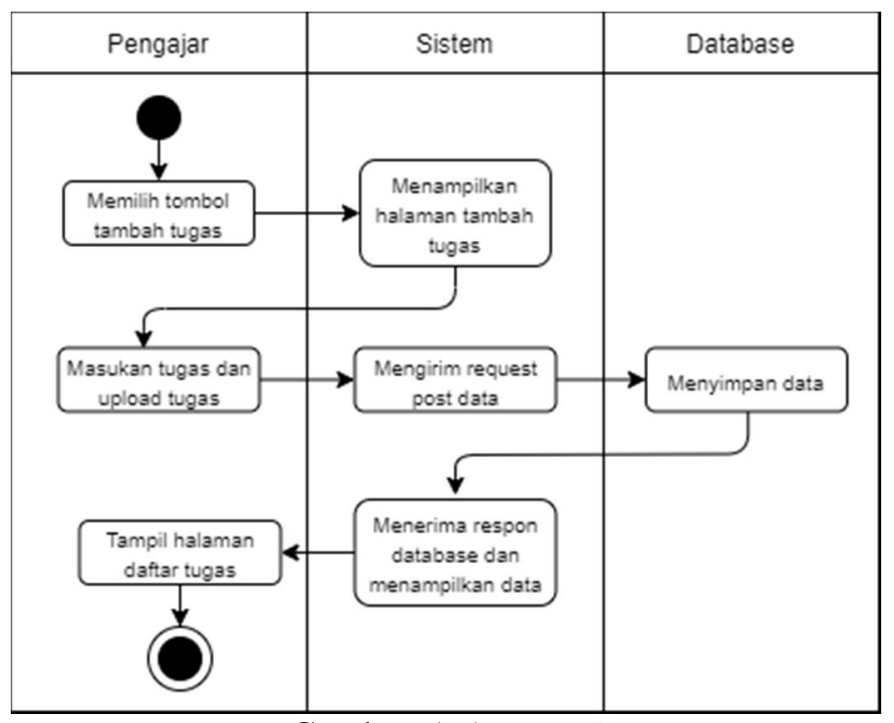

Gambar 5. Activity Diagram

Pada gambar 5 dapat dijelaskan, Pengajar akan menambahkan tugas dengan memilih tombol tambah tugas, kemudian sistem akan menampilkan halaman tambah tugas lalu pengajar akan memasukan tugas dan melakukan upload tugas. Setelah itu sistem akan mengirim request post data ke database sehingga database akan menyimpan data tersebut. Sistem akan menerima respon dari database yang berisi daftar tugas yang terbaru kemudian menampilkan kepada pengajajar. 


\section{HASIL DAN PEMBAHASAN}

\subsection{Tampilan Aplikasi}

Tampilan aplikasi adalah tampilan visual yang menjembatani antara pengguna dan sistem. Dibawah ini merupakan tampilan aplikasi yang dibuat dalam penelitian ini.

Tabel 1. Tampilan Aplikasi

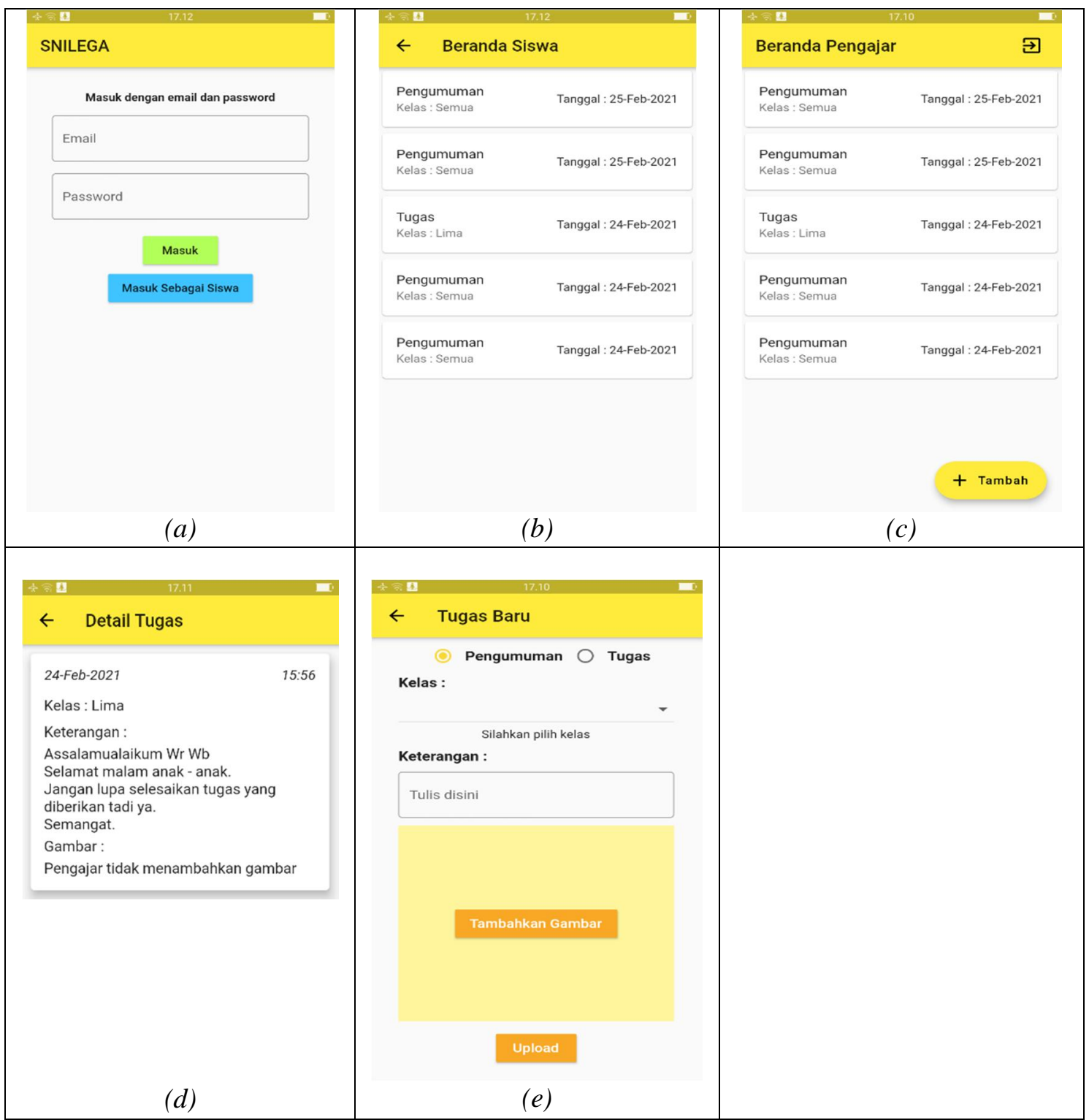

Gambar $a$ adalah tampilan login, sebelum mengakses ke halaman utama, user akan diarahkan ke halaman login terlebih dahulu. Jika akan masuk sebagai siswa maka pilih tombol masuk sebagai siswa tanpa harus memasukan email dan password. Sedangkan masuk sebagai pengajar maka diperlukan memasukan email dan password kemudian memilih tombol masuk.

Gambar $b$ adalah tampilan beranda siswa, tampilan ini merupakan tampilan utama setelah user melakukan login sebagai siswa. Tampilan ini berisi tugas atau pengumuman yang 
diberikan oleh pengajar. Siswa dapat melihat detail tugas atau pengumuman dengan menekan tugas tersebut.

Gambar $c$ adalah tampilan beranda pengajar, tampilan ini merupakan tampilan utama setelah user melakukan login sebagai siswa. Tampilan ini berisi tugas atau pengumuman. dan untuk melihat detail tugas atau pengumuman dengan menekan tugas tersebut. Pada saat berada dalam beranda pengajar, seorang pengajar dapat menambahkan tugas ataupun pengumuman dengan menakan tombol tambah pada bagian bawah tampilan.

Gambar $d$ adalah tampilan beranda pengajar, tampilan ini merupakan tampilan utama setelah user melakukan login sebagai siswa. Tampilan ini berisi tugas atau pengumuman. dan untuk melihat detail tugas atau pengumuman dengan menekan tugas tersebut. Pada saat berada dalam beranda pengajar, seorang pengajar dapat menambahkan tugas ataupun pengumuman dengan menakan tombol tambah pada bagian bawah tampilan.

Gambar $e$ adalah tampilan tambah tugas, tampilan ini merupakan tampilan untuk menambahkan tugas ataupun pengumuman baru. Untuk melakukan penambahan tugas, user harus login sebagai pengajar. Tugas ataupun pengumuman yang akan dikirimkan dapat dilampiri dengan gambar.

\subsection{Kode Program}

Dalam penelitian ini penulis menggunakan framework flutter dan bahasa pemrogaman dart. Dengan menggunakan flutter peneliti dimudahkan dalam pembangunan aplikasi dengan package yang telah disediakan. Dibawah ini contoh dari kode programnya.

void uploadImage () \{

String imageName = formatDate (dateNow, [yуyy, mm, dd, HH, $\mathrm{nn}$, ss]);

final Reference storageReference $=$

FirebaseStorage.instance.ref().child('ImageTasks'). child(imageName);

final UploadTask uploadTask = storageReference.putFile(imageTask);

uploadTask.then ( (TaskSnapshot taskSnapshot) \{

taskSnapshot.ref.getDownloadURL().then((imageUrl) \{ saveData (imageUrl);

\}) ;

\}) . catchError ( (error) \{

Fluttertoast.showToast (msg: error.tostring()); \}) ; \}

void saveData (String imageUrl) \{

dateFix = formatDate (dateNow, [dd, '-', M, '-', yYyy]);

dateId = formatDate (dateNow, [Yyyy, mm, dd, HH, nn, ss]);

timeTask = formatDate (dateNow, [HH, ':', nn]);

FirebaseFirestore. instance.collection ('postTasks') . add ( \{

'type': radioButtonItem,

'grade': selectedKelas.kelas,

'date': dateFix,

'time': timeTask,

'task': taskController.text,

'id': dateId,

'imageUrl': imageUrl,

\}) . whencomplete(() \{

Fluttertoast.showToast (msg: 'Berhasil Menambahkan');

\}). catcherror ( (error) \{

Fluttertoast.showToast (msg: error.tostring());

\}) ; \}

(a)

Yustian, et., al [Perancangan Aplikasi Mobile Learning Untuk Membantu Proses Pembelajaran Di SDN Lemahireng 03] 
Kode program $a$ adalah kode program untuk menambahkan tugas atau pengumuman baru yang mengandung gambar, dalam kode program tersebut berisi controller service agar dapat terkoneksi ke firebase sebagai database yang digunakan dan dapat menyimpan data tersebut ke database.

\subsection{Pengujian Sistem}

Pengujian sistem dilakukan untuk menguji fungsi - fungsi yang terdapat dalam sistem, apakah sudah berjalan dengan baik atau belum. Pengujian aplikasi dilakukan dengan cara alpha dan dilakukan metode blackbox testing dengan cara functional testing. Pengujian alpha adalah pengujian yang dilakukan oleh pihak internal, sebelum dilakukan Bersama client. Pada pengujian yang didasarkan pada setiap fungsinya, aplikasi dapat berjalan dengan ssemestinya. Pengujian aplikasi dapat ditunjukan pada table dibawah ini.

Tabel 2. Hasil Pengujian

\begin{tabular}{|c|c|c|c|c|}
\hline No & Model yang Diuji & $\begin{array}{l}\text { Hasil yang } \\
\text { Diharapkan }\end{array}$ & Hasil & Status \\
\hline 1 & $\begin{array}{l}\text { Nama : login pengajar, } \\
\text { Deskripsi : Pengujian verifikasi hak } \\
\text { akses, } \\
\text { Username : pengajar1@gmail.com, } \\
\text { Password : ***** } \\
\text { Aksi : klik tombol masuk sebagai } \\
\text { pengajar. }\end{array}$ & $\begin{array}{lr}\text { Masuk r } & \text { ke } \\
\text { halaman } & \text { beranda } \\
\text { pengajar. }\end{array}$ & $\begin{array}{l}\text { Masuk dan } \\
\text { menampilkan } \\
\text { halaman beranda } \\
\text { pengajar. }\end{array}$ & Valid \\
\hline 2 & $\begin{array}{l}\text { Nama : login siswa, } \\
\text { Deskripsi : Pengujian verifikasi hak } \\
\text { akses, } \\
\text { Aksi : klik tombol masuk sebagai } \\
\text { pelajar. }\end{array}$ & $\begin{array}{lr}\text { Masuk r } & \text { ke } \\
\text { halaman } & \text { beranda } \\
\text { pengajar. }\end{array}$ & $\begin{array}{l}\text { Masuk dan } \\
\text { menampilkan } \\
\text { halaman beranda } \\
\text { pengajar. }\end{array}$ & Valid \\
\hline 3 & $\begin{array}{l}\text { Nama : menambahkan tugas baru, } \\
\text { Deskripsi : upload tugas baru ke } \\
\text { database sesuai pengisian form, } \\
\text { Aksi : klik tombol upload. }\end{array}$ & $\begin{array}{l}\text { Jika berhasil tugas } \\
\text { baru masuk ke data } \\
\text { base dan berpindah } \\
\text { tampilan kehalaman } \\
\text { beranda. }\end{array}$ & $\begin{array}{l}\text { Berhasil } \\
\text { menambahkan } \\
\text { tugas dan } \\
\text { berpindah } \\
\text { kehalaman berana }\end{array}$ & Valid \\
\hline 4 & $\begin{array}{l}\text { Nama : detail tugas, } \\
\text { Deskripsi : melihat detail tugas, } \\
\text { Aksi : klik salah satu tugas } \\
\text { diberanda. }\end{array}$ & $\begin{array}{l}\text { Jika berhasil akan } \\
\text { masuk kehalaman } \\
\text { detail tugas. }\end{array}$ & $\begin{array}{lr}\text { Berhasil masuk } \\
\text { kehalaman } \\
\text { tugas }\end{array}$ & Valid \\
\hline
\end{tabular}

Merujuk pada tabel hasil pengujian, didapatkan hasil sistem dapat berjalan tanpa masalah dan sudah sesuai dengan kebutuhan pengguna. Pengujian beta adalah pengujian yang dilakukan setelah aplikasi diterima, diuji langsung dan wawancara dengan 11 pengajar dan operator sekolah SDN Lemahireng 03. Selain itu peneliti memberikan kuisioner, setelah membagikan kuisioner peneliti berhasil mendapatkan data sebagai berikut. 
Tabel 3. Parameter Nilai

\begin{tabular}{|c|c|}
\hline Skor Parameter & Nilai \\
\hline 5 & Sangat Setuju \\
\hline 4 & Setuju \\
\hline 3 & Netral \\
\hline 2 & Tidak Setuju \\
\hline 1 & Sangat Tidak Setuju \\
\hline
\end{tabular}

Tabel 4. Hasil Kuisioner Aplikasi

\begin{tabular}{|c|c|c|c|c|c|c|c|c|}
\hline \multirow{2}{*}{$\mathrm{No}$} & \multirow{2}{*}{ Pertanyaan } & \multicolumn{5}{|c|}{ Jawaban } & \multirow{2}{*}{ Jumlah } & \multirow{2}{*}{ Indeks } \\
\hline & & Ax5 & $\mathrm{Ax} 4$ & Ax3 & $\mathrm{Ax} 2$ & $\mathrm{Ax} 1$ & & \\
\hline \multicolumn{9}{|c|}{ User Interface } \\
\hline 1 & $\begin{array}{l}\text { Aplikasi mudah digunakan } \\
\text { oleh pengguna }\end{array}$ & 6 & 5 & 0 & 0 & 0 & 50 & $90 \%$ \\
\hline 2 & $\begin{array}{l}\text { Aplikasi berjalan mudah } \\
\text { dan ringan }\end{array}$ & 5 & 5 & 1 & 0 & 0 & 48 & $87 \%$ \\
\hline \multicolumn{9}{|c|}{ Fungsionalitas } \\
\hline 3 & $\begin{array}{lr}\text { Aplikasi } & \text { membantu } \\
\text { mempermudah } & \text { proses } \\
\text { pembelajaran } & \end{array}$ & 7 & 3 & 1 & 0 & 0 & 50 & $90 \%$ \\
\hline 4 & $\begin{array}{l}\text { Fungsi menambahkan } \\
\text { tugas atau pengumuman } \\
\text { berjalan dengan baik }\end{array}$ & 10 & 1 & 0 & 0 & 0 & 54 & $98 \%$ \\
\hline 5 & $\begin{array}{l}\text { Fungsi menampilkan tugas } \\
\text { berjalan dengan baik }\end{array}$ & 9 & 2 & 0 & 0 & 0 & 53 & $95 \%$ \\
\hline
\end{tabular}

Pada tabrl 3 merupakan standart dari penilaian parameter untuk mengatahui bagus tidaknya. Berdasarkan hasil yang diperoleh yang ditunjukan pada table 4, dan dilakukan perhitungan menggunakan skala Likert pada kolom indeks dengan menggunakan rumus (1).

$$
\text { Rumus Indeks }(\%)=\text { Total Skor/Y x 100\% }
$$

Skala Likert adalah pengukuran yang dikembangkan oleh Likert. Skala mempunyai empat atau lebih pertanyaan yang dikombinasikan sehingga membentuk sebuah skor atau nilai. Pada rumus (1) Y adalah skor tertinggi likert dikali jumlah responden, total skor adalah jumlah dari masing - masing skala.

Tabel 5. Interpretasi Nilai Kepuasan

\begin{tabular}{|c|c|}
\hline Skor Kepuasan & Nilai \\
\hline $80 \%-100 \%$ & Sangat Setuju \\
\hline $60 \%-79 \%$ & Setuju \\
\hline $40 \%-59 \%$ & Netral \\
\hline $20 \%-39 \%$ & Tidak Setuju \\
\hline $0 \%-19 \%$ & Sangat Tidak Setuju \\
\hline
\end{tabular}

Berdasarkan tabel 4 hasil kuisioner aplikasi, nilai rata - rata dari petanyaan pertama adalah 5 maka persentasenya $90 \%$, nilai rata - rata dari petanyaan kedua adalah 4,8 maka persentasenya $87 \%$, nilai rata - rata dari petanyaan ketiga adalah 5 maka persentasenya $90 \%$, nilai rata - rata dari petanyaan keempat adalah 5,4 maka persentasenya adalah 98\%, nilai rata - 
rata dari petanyaan kelima adalah 53\% maka persentasenya adalah 95\%. Berdasarkan hasil tersebut, persentase hasil klasifikasi dari setiap indeks dapat disimpulkan bahwa responden sangat setuju bahwa aplikasi tersebut membantu mempermudah proses pembelajaran, serta aplikasi tersebut mudah dalam penggunaannya.

\section{KESIMPULAN}

Berdasarkan penelitian dan pengujian yang dilakukan maka dapat disimpulkan bahwa aplikasi mobile e-learning ini berhasil dibangun menggunakan framework flutter. Penggunaan framework flutter memudahkan pengembang dalam penulisan kode program karena fitur dan package yang telah disediakan. Berdasarkan hasil pengujian dan hasil dari kuisioner yang diberikan pada pengajar dapat diketahui bahwa adanya aplikasi pembelajaran berbasis mobile ini dapat mempermudah proses pembelajaran seperti yang diharapkan pada tujuan dan manfaat penelitian ini, serta dapat memaksimalkan pembelajaran yang dilakukam, sehingga siswa dapat lebih mudah mendapatkan informasi pembelajaran.

\section{SARAN}

Adapun saran yang diperlukan adalah mengenai kinerja aplikasi, kedepannya diperlukan pengembangan lebih lanjut agar aplikasi lebih optimal. Selain itu keamanan pada aplikasi yang rentan terhadap serangan.

\section{UCAPAN TERIMA KASIH}

Penulis mengucapkan terima kasih kepada pihak yang memberikan dukungan secara langsung maupun dukungan secara tidak langsung.

\section{DAFTAR PUSTAKA}

[1] A. A. Utomo, A. Imron, And M. Syaiful. 2017, "Pengaruh Penjelasan Guru Terhadap Pemahaman Siswa pada Mata Pelajaran Sejarah," Pesagi (Jurnal Pendidik. dan Penelit. Sejarah), Vol. 5, No. 8, Pp. 1-12.

[2] H. Budiman. 2017, "Peran Teknologi Informasi dan Komunikasi Dalam Pendidikan," Al-Tadzkiyyah J. Pendidik. Islam, Vol. 8, No. 1, P. 31, Doi: 10.24042/Atjpi.V8i1.2095.

[3] I. W. K. Suwastika. 2018, "Pengaruh E-Learning Sebagai Salah Satu Media Pembelajaran Berbasis Teknologi Informasi Terhadap Motivasi Belajar Mahasiswa," J. Sist. dan Inform., Vol. 13, No. 1, Pp. 1-5,

[4] R. T. Sataloff, M. M. Johns, And K. M. Kost, "Pengaruh Teknologi Terhadap Pendidikan Di Abad 21."

[5] D. Ariani. 2018, "Komponen Pengembangan E-Learning," J. Pembelajaran Inov., Vol. 1, No. 1, Pp. 58-64, Doi: 10.21009/Jpi.011.09. 
[6] Y. Irawan, N. Susanti, And W. A. Triyanto. 2015, "Analisa dan Perancangan Sistem Pembelajaran Online (E-Learning) pada SMK Mambaul Falah Kudus," Simetris J. Tek. Mesin, Elektro dan Ilmu Komput., Vol. 6, No. 2, P. 345, Doi: 10.24176/Simet.V6i2.471.

[7] M. Andry Iqromi and Muh. Husein Baysha. 2018, "Pengaruh Media Komputer," Pengaruh Media Komput. Terhadap Prestasi Belajar Siswa, Vol. 3, No. April, Pp. 1-9.

[8] A. Asmurti, A. A. Unde, And T. Rahamma. 2018, "Dampak Penggunaan Smartphone Di Lingkungan Sekolah Terhadap Prestasi Belajar Siswa,” Kareba J. Ilmu Komun., Vol. 6, No. 2, P. 225, Doi: 10.31947/Kjik.V6i2.5318.

[9] G. Amirullah And R. Hardinata. 2017, "Pengembangan Mobile Learning Bagi Pembelajaran,” Jkkp (Jurnal Kesejaht. Kel. dan Pendidikan), Vol. 4, No. 02, Pp. 97-101, Doi: $10.21009 / \mathrm{Jkkp} .042 .07$.

[10] A. Santi And E. Prihatnani. 2018, “Perbandingan Metode Drill dan Metode Discovery Learning Ditinjau dari Hasil Belajar Matematika,” Pros. Semin. Nas. Mat., Vol. 1, Pp. 943-953.

[11] S. Sharipuddin, E. Effiyandi, and D. Febryanto. 2019, "Perancangan Aplikasi ELearning pada Mts Negeri 1 Merangin,” J. Process., Vol. 14, No. 1, P. 74, Doi: 10.33998/Processor.2019.14.1.576.

[12] W. E. Susanto And Y. G. A. Ayu, 2017, "Perancangan E-Learning Berbasis Web pada SMP Negeri 3 Patuk Gunungkidul Yogyakarta,” Bianglala Inform., Vol. 5, No. 2.

[13] R. S. Teuku Fadjar Shadek. 2017, "Pengembangan Aplikasi Sistem E-Learning pada Seluruh Mata Kuliah Dengan Menggunakan Program Hypertext Prepocessor (PHP) Dalam Rangka Peningkatan Mutu Proses dan Hasil Pembelajaran,” J. Protekinfo, Vol. 4, Pp. 1-18.

[14] M. Siregar And I. Permana. 2016, "Rancang Bangun Aplikasi Berbasis Mobile Untuk Navigasi Ke Alamat Pelanggan TV Berbayar (Studi Kasus: Indovision Cabang Pekanbaru) 1,” J. Rekayasa dan Manaj. Sist. Inf., Vol. 2, No. 1, Pp. 82-94, [Online]. Available: Www.Hostinger.Co.Id.

[15] Y. W. A. Rustam. 2017, “Jurnal Aplikasi Mobile,” J. Inf., Vol. Vi, No. 2, Pp. 88-99.

[16] U. Ardy, J. Desiana, and M. Rachmadi. 2018, "Pengembangan Aplikasi Perencana Wisata 'Plesir' Berbasis Android dan Ios,” Ijccs, Vol. X, No. X, Pp. 1-11.

[17] A. Sonita And R. F. Fardianitama. 2018, "Aplikasi E-Order Menggunakan Firebase dan Algoritme Knuth,” J. Pseudocode, Vol. 5, No. 2, Pp. 38-45. 